\title{
On the Preorder Strategy for Loss-Averse Newsvendor Model under CVaR Measure
}

\author{
Jingfu Huang $\mathbb{D}{ }^{1}{ }^{1}$ Bo Feng $\mathbb{D}^{2}{ }^{2}$ and Chengfei Wang ${ }^{1}$ \\ ${ }^{1}$ School of Management Science, Qufu Normal University, Rizhao, Shandong 276800, China \\ ${ }^{2}$ Business and Law Faculty, Deakin University, Locked Bag 20000, Geelong VIC 3220, Australia \\ Correspondence should be addressed to Jingfu Huang; jingfu_huang@126.com
}

Received 20 October 2021; Accepted 3 January 2022; Published 2 February 2022

Academic Editor: Xinsheng Xu

Copyright ( 2022 Jingfu Huang et al. This is an open access article distributed under the Creative Commons Attribution License, which permits unrestricted use, distribution, and reproduction in any medium, provided the original work is properly cited.

Due to rapid development of manufacturing and online retail, the life cycle of many products is becoming shorter and shorter. Hence, manufacturers may launch new products in selling season to maintain market share and attract new customers. Under these circumstances, manufacturers may release a presale information before the selling season, and the retailer correspondingly makes a preorder according to the estimation to the demand. For the case that the wholesale price rises gradually with time during the preselling period and the market demand is stochastic, based on minimizing the legacy loss via CVaR measure in risk management, we establish a loss-averse newsvendor's preordering decision model. By model analysis, we establish the closed form solution to the model and provide the optimal preordering time and preordering quantity to the retailer. Some numerical experiments are made to show the validity of the model, and some managerial insights are explored through the numerical experiments.

\section{Introduction}

As a promotion strategy in modern market, preselling mechanism is widely used by many enterprises in which the manufacturer releases a preselling information when the products are still in the production process [1-4]. For example, Apple provides customers a preordering service before a new generation of products comes to market [5] and the millet mobile phone industry adopted presale mechanism when it published the first generation cell phone [6]. Now, the preselling mechanism has been widely used in service industry, electronic manufacturing, and online retailing [7-12].

For the preselling mechanism, from the manufacturer's perspective, it can collect new product's demand information and reduce inventory risk in today's competitive market, and hence it can help the manufacturer predict the market potential demand and reduce inventory risk. For this, Cachon [8] compared inventory risks under push, pull, and preorder discount contracts between suppliers and retailers, Gilbert and Cvsa [13] examined manufacturers' wholesale price commitment decisions as well as issues related to presale timing, Boyaci and Özer [7] established a profit-maximization model in which a manufacturer collected advance sales information periodically prior to the regular sales season for a capacity decision, and Nasiry and Popescu [14] characterized the effect of anticipated regret on consumer decisions and on firm profits and policies in an advance selling context where buyers have uncertain valuations.

For the preselling mechanism, from the retailer's perspective, the retailer can receive a price discount for accepting the manufacturer's preselling, which will reduce the retailer's purchasing cost. For example, Amazon offered a $20 \%$ preorder discount for all new-to-be-released video games from 2016 to 2018 [12]. Furthermore, preselling guarantees that the retailer receives the items earlier, which is particularly valuable when the product may be hard to find in the spot selling period due to its popularity $[5,15,16]$. A second benefit of preselling is that the selling season demand can be more accurately forecasted because orders received in the preselling period may be correlated with the demand in 
the selling season. The retailer can update its demand forecast and adjust the order quantity accordingly to reduce excess inventory and stock out risks. In addition to reducing inventory risks, preselling takes advantage of changes in consumers product valuation uncertainty over time as noted by Xie and Shugan [17], Shugan and Xie [18], and Gundepudi et al. [19].

It should be noted that most research studies on this issue assume that supply chain participants are risk-neutral, whereas some scholars showed through empirical research that not all the decision-makers are of this type [20]. Thus, it is essential to take the retailers' behavior preference into considerations [21-23]. Due to this, the loss aversion theory is posed and is applied in many fields, such as portfolio optimization and supply chain management. In particular, the $\mathrm{CVaR}$ is a popular measure in describing decisionmaker's behavior preference for risk $[24,25]$ and has made a good success in quantifying and mitigating the potential risk in newsvendor problem [26-35].

In this paper, we consider a loss-averse newsvendor model in which the manufacturer will provide a preselling strategy to the retailer before the selling season. In the preselling period, the wholesale price increases with time. Since the demand during the selling season is stochastic, to minimize the retailer's legacy loss, the retailer should determine the preordering time and preordering quantity according to the estimation to the demand in the selling season. For this, we establish an optimal preordering decision model. By modeling analysis, we obtain the retailer's optimal preordering time and preordering quantity.

The remainder of this paper is organized as follows. Section 2 presents the notations and provides some necessary assumptions needed on the concerned problem. In Section 3, we establish an optimization model for the concerned problem. Section 4 provides the model solution and gives the retailer's optimal preorder policy. Section 5 presents numerical examples to illustrate the validity of the model. Some conclusions are drawn in the last section.

\section{Notation and Assumptions}

In this paper, we consider the newsvendor model with a preselling strategy and the retailer is risk-averse. More precisely, the planning horizon consists of two period$\mathrm{s}$ - preselling period and spot selling period. During the preselling period, the wholesale price of the item gradually increases with time (see Figure 1). Thus, to enjoy the lower wholesale price provided by the supplier, the retailer may

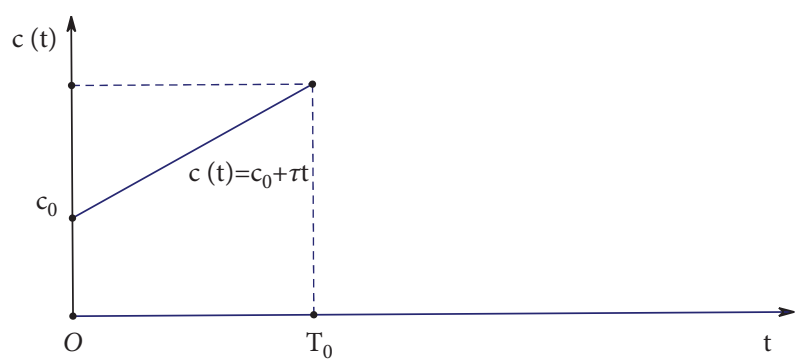

FIgURE 1: The variation of the wholesale price in the planning horizon.

make a preorder. However, the prepaid purchase cost would result in certain interest cost during the preordering period. Thus, the retailer should make a tradeoff between enjoying the benefit provided by the preselling strategy and bearing the interest cost of prepaid for the preorder. With this, the retailer should determine the preordering time and the preorder quantity so that his profit is maximized. To this end, we need the notations listed in Table 1.

For the concerned model, we assume that

(1) The retailer is risk-averse

(2) The whole price during the preordering period is $c(t)=c_{0}+\tau t$ for $t \in\left[0, T_{0}\right]$, where $\tau>0$ is a constant

(3) The demand during the spot selling period is random which obeys probability distribution with probability density function $f(x)$ and probability distribution function $F(x)$

\section{Model Formulation}

For the concerned inventory mechanism, since the wholesale price in the preselling period gradually increases with time and it is lower than the ordinary wholesale price, the retailer should determine the preordering time and the preorder quantity. Further, since the demand during the spot selling period is random, it is impossible to make a preorder such that the order quantity is equal to the demand; this means that there is always a risk of loss for any preorder. Then, the retailer's preorder decision will be affected by his attitude to the risk of loss. For this, we use the popular CVaR measure to describe his behavior preference for risk $[24,25]$. To this end, we first compute the retailer's loss function.

Suppose the preorder is made at $t_{d}$ with quantity $Q_{d}$. Then, from the assumption, the retailer's profit is

$$
\Pi\left(t_{d}, Q_{d}, D\right)=b \min \left(D, Q_{d}\right)-c\left(t_{d}\right) Q_{d}-\gamma\left(T_{0}-t_{d}\right) c\left(t_{d}\right) Q_{d}+r\left(Q_{d}-D\right)^{+},
$$

where $X^{+}=\max \{X, 0\}$, the first term is sale profit, the second term is the wholesale cost, the second term is the loan interest, and the last term is recycling profit.

Certainly, if the retailer's preorder quantity exactly meets the demand, i.e., $Q_{d}=D$, then the retailer can obtain the maximal profit $\left(b-c\left(t_{d}\right)\right) D-\gamma\left(T_{0}-t_{d}\right) c\left(t_{d}\right) D$. Then, for preorder made at $t_{d}$ with quantity $Q_{d}$, the retailer's loss is

$L\left(t_{d}, Q_{d}, D\right)=\left(b-c\left(t_{d}\right)-\gamma\left(T_{0}-t_{d}\right) c\left(t_{d}\right)\right) D-\Pi\left(t_{d}, Q_{d}, D\right)$. 
TABLE 1: Notations.

\begin{tabular}{lc}
\hline Symbol & Description \\
\hline$T_{0}$ & The ending time of preselling \\
$c_{0}$ & Wholesale price at the beginning of preselling \\
$b$ & Item selling price in spot market \\
$r$ & Item recycling price \\
$\tau$ & The wholesale price increasing coefficient \\
$D$ & Market demand in spot market \\
$Q_{d}$ & Retailer's preordering quantity (variable) \\
$t_{d}$ & Retailer's preordering time (variable) \\
$\gamma$ & The loan interest rate \\
$*$ & The optimal value \\
\hline
\end{tabular}

Using the fact that $\min \left(Q_{d}, D\right)=Q_{d}-\left(Q_{d}-D\right)^{+}$, the function can be written as

$$
L\left(t_{d}, Q_{d}, D\right)=\left(b-c\left(t_{d}\right)-\gamma\left(T_{0}-t_{d}\right)\right)\left(D-Q_{d}\right)+(b-r)\left(Q_{d}-D\right)^{+}
$$

For the confidence level $\alpha \in(0,1)$, the value-at-risk of the retailer's loss is

$$
\operatorname{VaR}_{\alpha}\left(L\left(t_{d}, Q_{d}, D\right)\right)=\inf \left\{y \mid \operatorname{Pr}\left\{L\left(t_{d}, Q_{d}, D\right) \leq y\right\} \geq \alpha\right\},
$$

which represents the minimum loss under the confidence level $\alpha$. As a risk-averse decision maker, the retailer may take $\mathrm{VaR}$ as the targeted loss and pay more attention to the loss above a given target level $[24,25]$. This yields the following CVaR measure to describe the retailer's behavior preference for risk:

$$
\mathrm{CVaR}_{\alpha}\left(L\left(t_{d}, Q_{d}, D\right)\right)=\frac{1}{1-\alpha} E\left(L\left(t_{d}, Q_{d}, D\right) \mid L\left(t_{d}, Q_{d}, D\right) \geqslant \operatorname{VaR}_{\alpha}\left(L\left(t_{d}, Q_{d}, D\right)\right)\right)
$$

To facilitate computing of the CVaR, Rockafellar and Uryasev [25] introduced the following auxiliary function:

$$
H_{\alpha}\left(t_{d}, Q_{d}, y\right)=y+\frac{1}{1-\alpha} E\left[L\left(t_{d}, Q_{d}, D\right)-y\right]^{+},
$$

which transforms the optimization problem

$$
\min _{t_{d}, Q_{d}} \operatorname{CVaR}_{\alpha}\left(L\left(t_{d}, Q_{d}, D\right)\right)
$$

as the following minimization problem:

$$
\min _{t_{d}, Q_{d}, y}\left(y+\frac{1}{1-\alpha} E\left[L\left(t_{d}, Q_{d}, D\right)-y\right]^{+}\right) .
$$

In the following, we will give a closed form solution to the optimization problem and hence present the retailer's optimal preordering time and optimal preorder quantity.

\section{Model Solution}

Certainly, problem (1) can be written as

$$
\min _{t_{d}} \min _{Q_{d}, y}\left(y+\frac{1}{1-\alpha} E\left[L\left(t_{d}, Q_{d}, D\right)-y\right]^{+}\right) .
$$

In the following, we first solve the inner problem w.r.t. $Q_{d}$ and $y$ and then solve the outer problem w.r.t. $t_{d}$. For the inner problem, i.e.,

$$
\min _{Q_{d}, y}\left(y+\frac{1}{1-\alpha} E\left[L\left(t_{d}, Q_{d}, D\right)-y\right]^{+}\right),
$$

we have the following conclusion.

Theorem 1. For fixed preordering time $t_{d}$ and confidence level $\alpha \in[0,1)$, the retailer optimal preorder quantity is

$$
Q_{d}^{*}\left(t_{d}\right)=\frac{(c-r) F^{-1}\left((1-\alpha)(b-c / b-r)+(b-c) F^{-1}((1-\alpha)(b-c) / b-r+\alpha)\right.}{b-r}
$$

with 


$$
y^{*}\left(t_{d}\right)=\frac{(c-r)(b-c)\left(F^{-1}((1-\alpha)(b-c) / b-r+\alpha)-F^{-1}((1-\alpha)(b-c / b-r))\right.}{b-r},
$$

where $c=-\gamma \tau t_{d}^{2}+\left(\tau+\gamma \tau T_{0}-\gamma c_{0}\right) t_{d}+\gamma T_{0} c_{0}+c_{0}$.

Proof. For problem (3), we first consider the minimization problem w.r.t. $y$ for fixed $Q_{d}$ and then solve the problem w.r.t. $Q_{d}$.
By $L\left(t_{d}, Q_{d}, D\right)=(b-c)\left(D-Q_{d}\right)+(b-r)\left(Q_{d}-D\right)^{+}$, the objective function of problem (3) can be written as

$$
\begin{aligned}
H_{\alpha}\left(t_{d}, Q_{d}, y\right) & =y+\frac{1}{1-\alpha} \int_{0}^{+\infty}\left(L\left(t_{d}, Q_{d}, x\right)-y\right)^{+} f(x) \mathrm{d} x \\
& =y+\frac{1}{1-\alpha} \int_{0}^{Q_{d}}\left[c\left(x-Q_{d}\right)-y\right]^{+} f(x) \mathrm{d} x+\frac{1}{1-\alpha} \int_{Q_{d}}^{+\infty}\left[(b-c)\left(x-Q_{d}\right)-y\right]^{+} f(x) \mathrm{d} x .
\end{aligned}
$$

We break the discussion into to two cases.

Case 1. $y \geq(c-r) Q_{d}$. In this case,

$$
H_{\alpha}\left(t_{d}, Q_{d}, y\right)=y+\frac{1}{1-\alpha} \int_{Q_{d}+y / b-c}^{+\infty}\left[(b-c)\left(x-Q_{d}\right)-y\right]^{+} f(x) \mathrm{d} x .
$$

Computing the partial derivative respect to $Q_{d}$ yields

$$
\frac{\partial H_{\alpha}\left(t_{d}, Q_{d}, y\right)}{\partial y}=1-\frac{1}{(1-\alpha)}\left[1-F\left(Q_{d}+\frac{y}{b-c}\right)\right] \text {. }
$$

From the monotony increasing property of $F(x)$ and $\lim _{x \longrightarrow+\infty} F(x)=1$, we conclude that $\partial H_{\alpha}\left(t_{d}, Q_{d}, y\right) / \partial y \geq 0$ for sufficiently large $y$. If $\partial H_{\alpha}\left(t_{d}, Q_{d}, y\right) /\left.\partial y\right|_{y=(c-r) Q_{d}} \leq 0$, then the stationary point $y=(b-c)\left(F^{-1}(\alpha)-Q_{d}\right)$ is the minimum point of the objective function. Otherwise, $H_{\alpha}\left(t_{d}, Q_{d}, y\right)$ reaches the minimum in the interval $\left[0,(c-r) Q_{d}\right]$, and this boils down to Case 2 discussed as follows.

Case 2. $0 \leq y \leq(c-r) Q_{d}$. In this case,

$H_{\alpha}\left(t_{d}, Q_{d}, y\right)=y+\frac{1}{1-\alpha} \int_{0}^{Q_{d}-y / c-r}\left[(c-r)\left(Q_{d}-x\right)-y\right] f(x) \mathrm{d} x+\frac{1}{1-\alpha} \int_{Q_{d}+y / b-c}^{+\infty}\left[(b-c)\left(x-Q_{d}\right)-y\right] f(x) \mathrm{d} x$.

Then,

$$
\frac{\partial H_{\alpha}\left(t_{d}, Q_{d}, y\right)}{\partial y}=1-\frac{1}{(1-\alpha)}\left[1+F\left(Q_{d}-\frac{y}{c-r}\right)-F\left(Q_{d}+\frac{y}{r-c}\right)\right] .
$$

Certainly, $\quad \partial H_{\alpha}\left(t_{d}, Q_{d}, y\right) /\left.\partial y\right|_{y=0}=-\alpha / 1-\alpha<0 . \quad$ If $\mathrm{Q} \leq b-c / b-r F^{-1}(\alpha)$, then

$$
\frac{\partial H_{\alpha}\left(t_{d}, Q_{d}, y\right)}{\partial y}\left((c-r) Q_{d}\right)=\left[1-F\left(Q_{d}+\frac{c-r}{b-c}\right)\right] \geq 0 .
$$

The case boils down to Case 1 . If $Q_{d} \geq b-c / b-r F^{-1}(\alpha)$, then the minimum will be attained at the stationary point of the objective function, i.e., the root of the following equation denoted by $y_{2}^{*}$ :

$$
F\left(Q_{d}+\frac{y}{b-c}\right)-F\left(Q_{d}-\frac{y}{c-r}\right)=\alpha .
$$

So, for any fixed $Q_{d}$, the optimal solution of the optimization problem $\min _{y} H_{\alpha}\left(t_{d}, Q_{d}, y\right)$ is

$$
y^{*}= \begin{cases}(b-c)\left(F^{-1}(\alpha)-Q_{d}\right), & \text { if } Q_{d} \leq \frac{b-c}{b-r} F^{-1}(\alpha), \\ y_{2}^{*}, & \text { if } Q_{d} \geq \frac{b-c}{b-r} F^{-1}(\alpha) .\end{cases}
$$

Next, we consider minimization problem: 


$$
\min _{Q_{d}} H_{\alpha}\left(t_{d}, Q_{d}, y^{*}\right) .
$$

Case 3. $Q_{d} \leq b-c / b-r F^{-1}(\alpha)$. In this case, it follows from $y^{*}=(b-c)\left(F^{-1}(\alpha)-Q_{d}\right)$ that

For this, we break the discussion into two cases.

$$
H_{\alpha}\left(t_{d}, Q_{d}, y^{*}\right)=(b-c)\left(F^{-1}(\alpha)-Q_{d}\right)+\int_{F^{-1}(\alpha)}^{+\infty}\left[(b-c)\left(x-F^{-1}(\alpha)\right)\right] f(x) \mathrm{d} x
$$

Using the fact that

$$
\frac{\partial H_{\alpha}\left(t_{d}, Q_{d}, y^{*}\right)}{\partial Q_{d}}=-(b-c)<0
$$

we conclude that the function is monotonically decreasing in $\left[0, b-c / b-r F^{-1}(\alpha)\right]$. Hence, function $H_{\alpha}\left(t_{d}, Q_{d}, y^{*}\right)$ reaches minimum in interval $\left[b-c / b-r F^{-1}(\alpha),+\infty\right)$, and this boils down to Case 4 discussed as follows.

Case 4. $Q_{d} \geq b-c / b-r F^{-1}(\alpha)$. In this case, $y=y_{2}^{*}$. Then,

$H_{\alpha}\left(t_{d}, Q_{d}, y^{*}\right)=y^{*}+\frac{1}{1-\alpha} \int_{0}^{Q_{d}-y^{*} / c-r}\left[(c-r)\left(Q_{d}-D\right)-y^{*}\right] f(D) \mathrm{d} D+\frac{1}{1-\alpha} \int_{Q_{d}+y^{*} / b-c}^{+\infty}\left[(b-c)\left(D-Q_{d}\right)-y^{*}\right] f(D) \mathrm{d} D$,

and

$$
\frac{\partial H_{\alpha}\left(t_{d}, Q_{d}, y^{*}\right)}{\partial Q_{d}}=\frac{1}{1-\alpha}\left[(c-r) F\left(Q_{d}-\frac{y^{*}}{c-r}\right)-\left(b-c\left(t_{d}\right)\right)\left(1-F\left(Q_{d}+\frac{y^{*}}{b-c}\right)\right)\right] .
$$

Solving equation $\partial H_{\alpha}\left(t_{d}, Q_{d}, y^{*}\right) / \partial Q_{d}=0$, i.e., yields the optimal preorder quantity

$c F\left(Q_{d}-\frac{y^{*}}{c-r}\right)+(b-c)\left(F\left(Q_{d}+\frac{y^{*}}{b-c}\right)\right)=b-c$,

$$
Q_{d}^{*}\left(t_{d}\right)=\frac{(c-r) F^{-1}((1-\alpha)(b-c) / b-r)+(b-c) F^{-1}((1-\alpha)(b-c) / b-r+\alpha)}{b-r},
$$

and

$$
y^{*}\left(t_{d}\right)=\frac{(c-r)(b-c)\left(F^{-1}((1-\alpha)(b-c) / b-r+\alpha)-F^{-1}((1-\alpha)(b-c) / b-r)\right)}{b-r}
$$

This completes the proof of the assertion.

Now, consider the out problem of optimization problem (2), i.e., minimization problem

$$
\min _{t_{d}}\left(y^{*}+\frac{1}{1-\alpha} E\left[L\left(t_{d}, Q_{d}^{*}, D\right)-y^{*}\right]^{+}\right) .
$$

For this, we have the following conclusion.

Theorem 2. For the risk-averse retailer with confidence level $\alpha$, the retailer's optimal preordering time is 
$t_{d}^{*}= \begin{cases}\tilde{t}_{d}, & \text { if } \tilde{t}_{d} \in\left[0, T_{0}\right], \phi\left(\widetilde{t}_{d}\right) \leq 0, \min \left\{\phi(0), \phi\left(T_{0}\right)\right\}, \\ 0, & \text { if } \tilde{t}_{d} \in\left[0, T_{0}\right], \phi(0) \leq \min \left\{\phi\left(\tilde{t}_{d}\right), \phi\left(T_{0}\right)\right\} \\ T_{0}, & \text { if } \tilde{t}_{d} \in\left[0, T_{a} 0, \phi\left(T_{0}\right) \leq \min \left\{\phi\left(\widetilde{t}_{d}\right), \phi(0)\right\}\right. \\ 0, & \text { if } \tilde{t}_{d} \notin\left[0, T_{0}\right], \phi(0) \leq \phi\left(T_{0}\right), \\ T_{0}, & \text { otherwise, }\end{cases}$

$$
\begin{aligned}
\phi\left(t_{d}\right)= & \frac{\left(-\gamma \tau t_{d}^{2}+\left(\tau+\gamma \tau T_{0}-\gamma c_{0}\right) t_{d}+\gamma \tau T_{0}+c_{0}-r\right)\left(b+\gamma \tau t_{d}^{2}-\left(\tau+\gamma \tau T_{0}-i c_{0}\right) t_{d}-\gamma \tau T_{0}-c_{0}\right)}{b-r} \\
& \left(F^{-1}\left(\frac{(1-\alpha)\left(b+\gamma \tau t_{d}^{2}-\left(\tau+\gamma \tau T_{0}-\gamma c_{0}\right) t_{d}-\gamma \tau T_{0}-c_{0}\right)}{b-r}+\alpha\right)\right. \\
& \left.-F^{-1}\left(\frac{(1-\alpha)\left(b+\gamma \tau t_{d}^{2}-\left(\tau+\gamma \tau T_{0}-\gamma c_{0}\right) t_{d}-\gamma \tau T_{0}-c_{0}\right)}{b-r}\right)\right),
\end{aligned}
$$

and $\widetilde{t}_{d}$ is the root of the equation $\phi^{\prime}\left(t_{d}\right)=0$. Correspondingly,

the optimal preorder quantity is

$$
\begin{aligned}
Q_{d}^{*}= & \frac{\left(-\gamma \tau t_{d}^{2}+\left(\tau+\gamma \tau T_{0}-\gamma c_{0}\right) t_{d}+\gamma \tau T_{0}+c_{0}-r\right) F^{-1}\left((1-\alpha)\left(b+\gamma \tau t_{d}^{2}-\left(\tau+\gamma \tau T_{0}-\gamma c_{0}\right) t_{d}-\gamma \tau T_{0}-c_{0}\right) / b-r\right)}{b-r} \\
& +\frac{\left(\left(b+\gamma \tau t_{d}^{2}-\left(\tau+\gamma \tau T_{0}-\gamma c_{0}\right) t_{d}-\gamma \tau T_{0}-c_{0}\right) F^{-1}\left((1-\alpha)\left(b+\gamma \tau t_{d}^{2}-\left(\tau+\gamma \tau T_{0}-\gamma c_{0}\right) t_{d}-\gamma \tau T_{0}-c_{0}\right) / b-r+\alpha\right)\right.}{b-r} .
\end{aligned}
$$

Proof. From Theorem 1, we know that the objection function of minimization problem (4) can be written as

$$
\begin{aligned}
\phi\left(t_{d}\right)= & \frac{(c-r)(b-r)\left(F^{-1}\left((1-\alpha)(b-c / b-r+\alpha)-F^{-1}((1-\alpha)(b-c) / b-r)\right)\right.}{b-r} \\
= & \frac{\left(-\gamma \tau t_{d}^{2}+\left(\tau+\gamma \tau T_{0}-\gamma c_{0}\right) t_{d}+\gamma \tau T_{0}+c_{0}-r\right)\left(b+\gamma \tau t_{d}^{2}-\left(\tau+\gamma \tau T_{0}-\gamma c_{0}\right) t_{d}-\gamma \tau T_{0}-c_{0}\right)}{b-r} \\
& \left(F^{-1}\left(\frac{(1-\alpha)\left(b+\gamma \tau t_{d}^{2}-\left(\tau+\gamma \tau T_{0}-\gamma c_{0}\right) t_{d}-\gamma \tau T_{0}-c_{0}\right)}{b-r}+\alpha\right)\right. \\
& \left.-F^{-1}\left(\frac{(1-\alpha)\left(b+\gamma \tau t_{d}^{2}-\left(\tau+\gamma \tau T_{0}-\gamma c_{0}\right) t_{d}-\gamma \tau T_{0}-c_{0}\right)}{b-r}\right)\right)
\end{aligned}
$$

To compute its minimum, we consider its derivative 


$$
\begin{aligned}
\phi^{\prime}\left(t_{d}\right)= & \frac{\left(b+r+2 \gamma \tau t_{d}^{2}-\left(\tau+\gamma \tau T_{0}-\gamma c_{0}\right) t_{d}-\gamma \tau T_{0}-c_{0}\right)\left(-2 \gamma \tau t_{d}+\tau+\gamma \tau T_{0}-\gamma c_{0}\right)}{b-r} \\
& \left(F^{-1}\left(\frac{(1-\alpha)\left(b+\gamma \tau t_{d}^{2}-\left(\tau+\gamma \tau T_{0}-\gamma c_{0}\right) t_{d}-\gamma \tau T_{0}-c_{0}\right)}{b-r}+\alpha\right)\right. \\
& \left.-F^{-1}\left(\frac{(1-\alpha)\left(b+\gamma \tau t_{d}^{2}-\left(\tau+\gamma \tau T_{0}-\gamma c_{0}\right) t_{d}-\gamma \tau T_{0}-c_{0}\right)}{b-r}\right)\right) \\
& \left.+\frac{\left(-\gamma \tau t_{d}^{2}+\left(\tau+\gamma \tau T_{0}-\gamma c_{0}\right) t_{d}+\gamma \tau T_{0}+c_{0}-r\right)}{(b-r)^{2}}\right) \\
& \frac{\left(b+\gamma \tau t_{d}^{2}-\left(\tau+\gamma \tau T_{0}-\gamma c_{0}\right) t_{d}-\gamma \tau T_{0}-c_{0}\right)}{f\left((1-\alpha)\left(b+\gamma \tau t_{d}^{2}-\left(\tau+\gamma \tau T_{0}-\gamma c_{0}\right) t_{d}-\gamma \tau T_{0}-c_{0}\right) / b-r+\alpha\right)} \\
& \left.\left(1-\alpha+\gamma \tau t_{d}^{2}-\left(\tau+\gamma \tau T_{0}-\gamma c_{0}\right) t_{d}-\gamma \tau T_{0}-c_{0}\right) / b-r\right) \\
& \left(F^{-1}\left(\frac{(1-\alpha)\left(b+\gamma \tau t_{d}^{2}-\left(\tau+\gamma \tau T_{0}-\gamma c_{0}\right) t_{d}-\gamma \tau T_{0}-c_{0}\right)}{b-r}\right)\right. \\
& \left(\frac{(1-\alpha)\left(b+\gamma \tau t_{d}^{2}-\left(\tau+\gamma \tau T_{0}-\gamma c_{0}\right) t_{d}-\gamma \tau T_{0}-c_{0}\right)}{b-r}+\alpha\right) .
\end{aligned}
$$

If equation $\phi^{\prime}\left(t_{d}\right)=0$ is inconsistent, then function $\phi(t)$ reaches its minimum at 0 or $T_{0}$; otherwise, we denote $\widetilde{t}_{d}=\operatorname{argmin}\left\{\phi\left(t_{d}\right) \mid \phi^{\prime}\left(t_{d}\right)=0\right\}$. Then, if $\widetilde{t}_{d} \notin\left[0, T_{0}\right]$, function $\phi\left(t_{d}\right)$ reaches its minimum at 0 or $T_{0}$; if $\tilde{t}_{d} \in\left[0, T_{0}\right]$, then $\phi\left(t_{d}\right)$ reaches its minimum at 0 or $\tilde{t}_{d}$ or $T_{0}$.

From the discussion above, we can obtain the retailer's optimal preordering time

$$
t^{*}= \begin{cases}\tilde{t}_{d}, & \text { if } \tilde{t} \in\left[0, T_{0}\right], \phi\left(\tilde{t}_{d}\right) \leq 0, \min \left\{\phi(0), \phi\left(T_{0}\right)\right\} \\ 0, & \text { if } \tilde{t} \in\left[0, T_{0}\right], \phi(0) \leq \min \left\{\phi\left(\tilde{t}_{d}\right), \phi\left(T_{0}\right)\right\} \\ T_{0}, & \text { if } \tilde{t}_{d} \in\left[0, T_{0}\right], \phi\left(T_{0}\right) \leq \min \left\{\phi\left(\tilde{t}_{d}\right), \phi(0)\right\} \\ 0, & \text { if } \tilde{t}_{d} \notin\left[0, T_{0}\right], \phi(0) \leq \phi\left(T_{0}\right) \\ T_{0}, & \text { otherwise, }\end{cases}
$$

and the optimal preorder quantity

$$
\begin{aligned}
Q_{d}^{*}= & \frac{\left(-\gamma \tau t_{d}^{2}+\left(\tau+\gamma \tau T_{0}-\gamma c_{0}\right) t_{d}+\gamma \tau T_{0}+c_{0}-r\right) F^{-1}\left((1-\alpha)\left(b+\gamma \tau t_{d}^{2}-\left(\tau+\gamma \tau T_{0}-\gamma c_{0}\right) t_{d}-\gamma \tau T_{0}-c_{0}\right) / b-r\right)}{b-r} \\
& +\frac{\left(\left(b+\gamma \tau t_{d}^{2}-\left(\tau+\gamma \tau T_{0}-\gamma c_{0}\right) t_{d}-\gamma \tau T_{0}-c_{0}\right) F^{-1}\left((1-\alpha)\left(b+\gamma \tau t_{d}^{2}-\left(\tau+\gamma \tau T_{0}-\gamma c_{0}\right) t_{d}-\gamma \tau T_{0}-c_{0}\right) / b-r+\alpha\right)\right.}{b-r} .
\end{aligned}
$$

From Theorems 1 and 2, we can present the following algorithm for computing the retailer's optimal preordering time and optimal preordering quantity.
In the next section, we will make some numerical experiments to test the efficiency of the proposed algorithm. 
Step 1. Input parameters $b, c_{0}, \tau, r, T_{0}, \alpha, \gamma, f(x), F^{-1}(x)$.

Step 2. Define function

$\phi\left(t_{d}\right)=\left(-\gamma \tau t_{d}^{2}+\left(\tau+\gamma \tau T_{0}-\gamma c_{0}\right) t_{d}+\gamma \tau T_{0}+c_{0}-r\right)\left(b+\gamma \tau t_{d}^{2}-\left(\tau+\gamma \tau T_{0}-\gamma c_{0}\right) t_{d}-\gamma \tau T_{0}-c_{0}\right) / b-r$

$\left(F^{-1}\left((1-\alpha)\left(b+\gamma \tau t_{d}^{2}-\left(\tau+\gamma \tau T_{0}-\gamma c_{0}\right) t_{d}-\gamma \tau T_{0}-c_{0}\right) / b-r+\alpha\right)-F^{-1}\left((1-\alpha)\left(b+\gamma \tau t_{d}^{2}-\left(\tau+\gamma \tau T_{0}-\gamma c_{0}\right) t_{d}-\gamma \tau T_{0}-\right.\right.\right.$

$\left.\left.c_{0}\right) / b-r\right)$ ) and solve equation $\phi^{\prime}\left(t_{d}\right)=0$ to obtain $\tilde{t}_{d}$. If $\tilde{t}_{d}<0$ or $\tilde{t}_{d}>T_{0}$, set $\tilde{t}_{d}=0$.

Step 3. If $\phi\left(\widetilde{t}_{d}\right) \leq \min \left(\phi(0), \phi\left(T_{0}\right)\right)$, then set $t_{d}^{*}=\widetilde{t}_{d}$, else set $t_{d}^{*}=T_{0}$, goto next step.

Step 4. Compute $Q_{d}^{*}=\left(-\gamma \tau t_{d}^{2}+\left(\tau+\gamma \tau T_{0}-\gamma c_{0}\right) t_{d}+\gamma \tau T_{0}+c_{0}-r\right) F^{-1}\left((1-\alpha)\left(b+\gamma \tau t_{d}^{2}-\left(\tau+\gamma \tau T_{0}-\gamma c_{0}\right) t_{d}-\gamma \tau T_{0}-c_{0}\right) / b-\right.$

$r) / b-r+\left(\left(b+\gamma \tau t_{d}^{2}-\left(\tau+\gamma \tau T_{0}-\gamma c_{0}\right) t_{d}-\gamma \tau T_{0}-c_{0}\right) F^{-1}\left((1-\alpha)\left(b+\gamma \tau t_{d}^{2}-\left(\tau+\gamma \tau T_{0}-\gamma c_{0}\right) t_{d}-\gamma \tau T_{0}-c_{0}\right) / b-r+\alpha\right) / b-r\right.$

Step 5. Output $t_{d}^{*}, Q_{d}^{*}$.

Algorithm 1: The algorithm to compute the optimal preordering time and the optimal preorder quantity.

\section{Numerical Example}

In this section, we test the efficiency of the proposed model by three numerical examples and make some numerical sensitivity analysis to test the influence of the involved parameters on the retailer's optimal preorder strategy. Some data of the considered examples are taken from [31].

Example 1. Considering the preorder inventory mechanism with $b=70, c_{0}=25, \gamma=0.07, \tau=0.3, r=15, T_{0}=50$, and $\alpha=0.95$, the demand obeys the exponential distribution with probability density function $f(x)=1 / 150 \exp (-x / 150), x \in[0,+\infty)$.

For this problem, by Algorithm 1, retailer's optimal preordering time is $t_{d}^{*}=0.37$, and optimal preordering quantity is $Q_{d}^{*}=291$.

To better understand the influence of the parameters involved in the model on the retailer's optimal preorder strategy, we conduct some parameters sensitivity analysis on the model.

For inventory mechanism of Example 1, we let retailer's confidence level $\alpha$ increase from 0.90 to 0.99 , while keeping other parameters unchanged. The numerical results are shown in Figures 2 and 3 from which we see that with the increase in the retailer's confidence level of $\alpha$, the optimal preordering time is decreasing and the retailer's optimal preordering quantity is also increasing.

For the inventory mechanism, we let the selling price $b$ increase from 65 to 75, while keeping other parameters unchanged. The numerical results are shown in Figures 4 and 5 , from which we can see that, when $b$ increases from 65 to 75 , the retailer's optimal preordering time is also increasing, while the optimal preordering quantity is decreasing.

For the inventory mechanism considered in Example 1, we let $c_{0}$ increase from 20 to 30 , while keeping other parameters unchanged. The numerical results are shown in Figures 6 and 7, from which we can see that, when $c_{0}$ increases from 20 to 30 , the retailer's optimal preordering time is decreasing, while the optimal preordering quantity is increasing.

For the inventory mechanism considered in Example 1, we let $\gamma$ increase from 0.07 to 0.09 , while keeping other

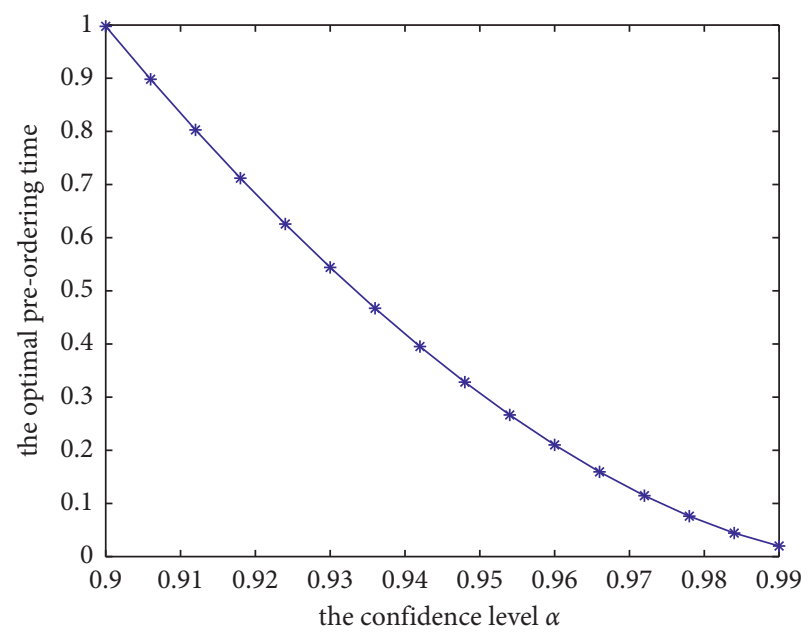

FIGURE 2: Influence of $\alpha$ on the retailer's preordering time.

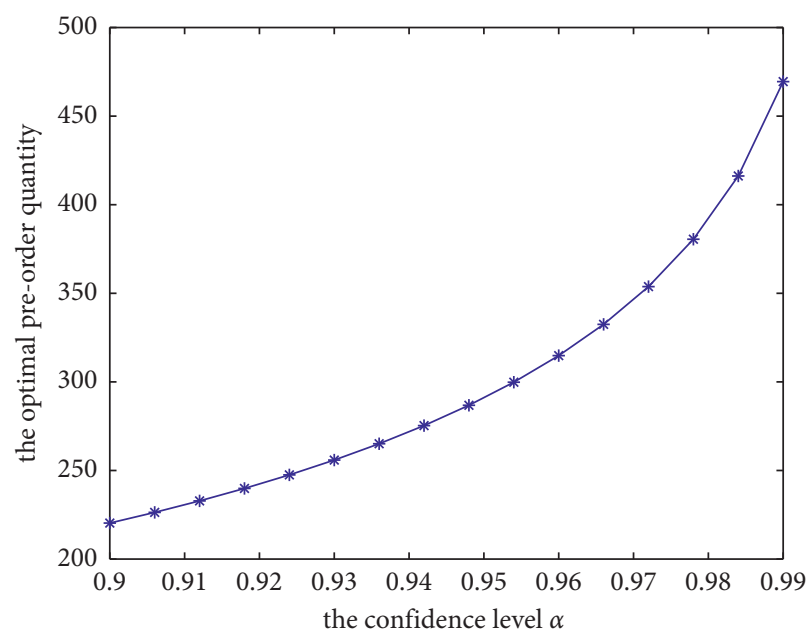

FIGURE 3: Influence of $\alpha$ on the retailer's preordering quantity.

parameters unchanged, the numerical results are shown in Figures 8 and 9, from which we can see that, if $\gamma$ goes from 0.05 to 0.09 , the retailer's preordering time is increasing in $\gamma$ and the retailer's optimal preordering quantity is also increasing in $\gamma$. 


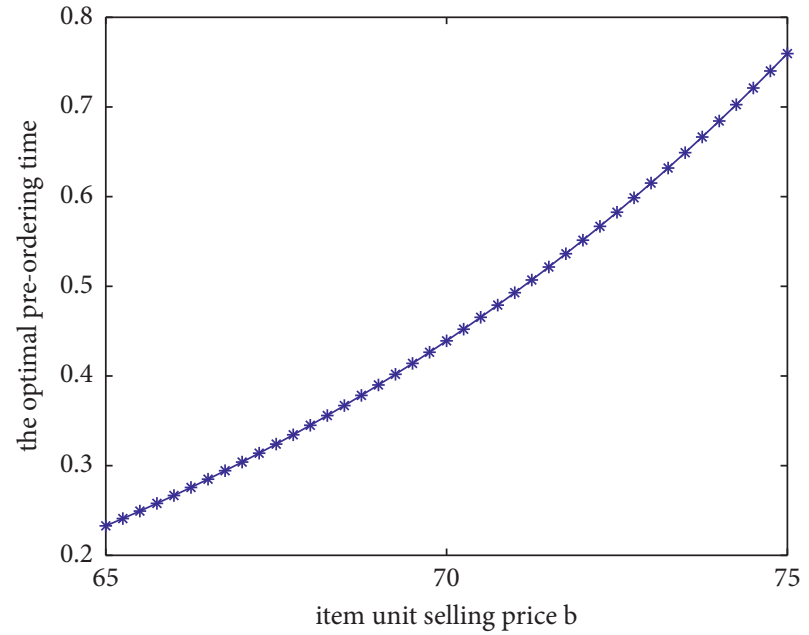

FIGURE 4: Influence of $b$ on the retailer's preordering time.

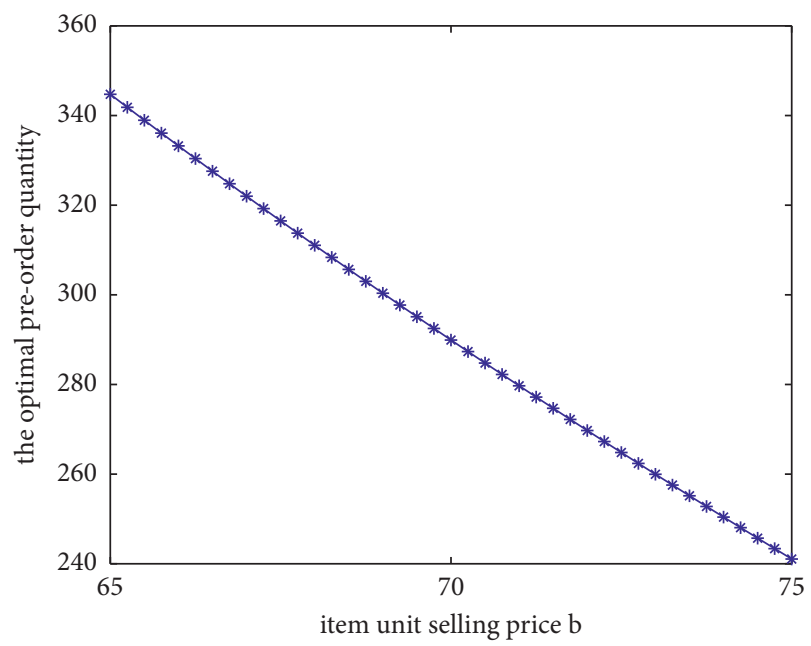

FIGURE 5: Influence of $b$ on the retailer's preordering quantity.

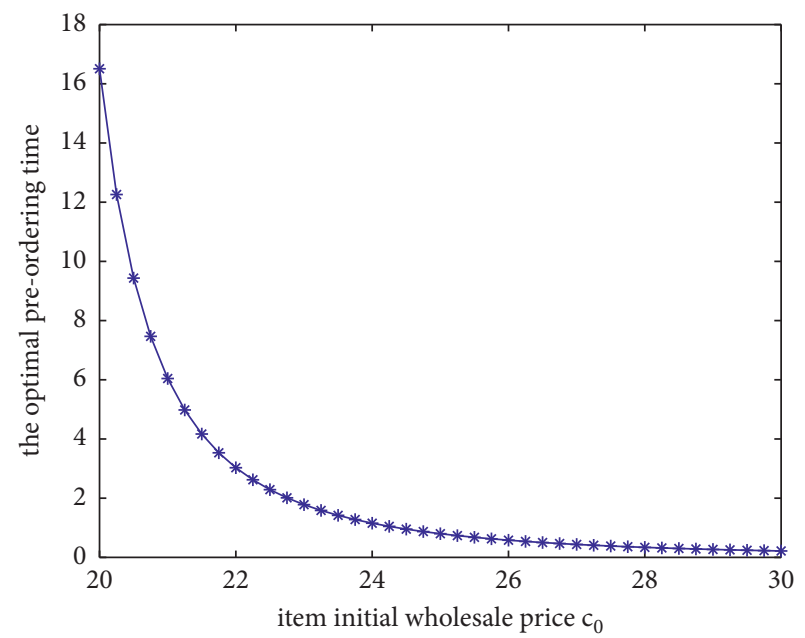

Figure 6: Influence of $c_{0}$ on the retailer's preordering time.

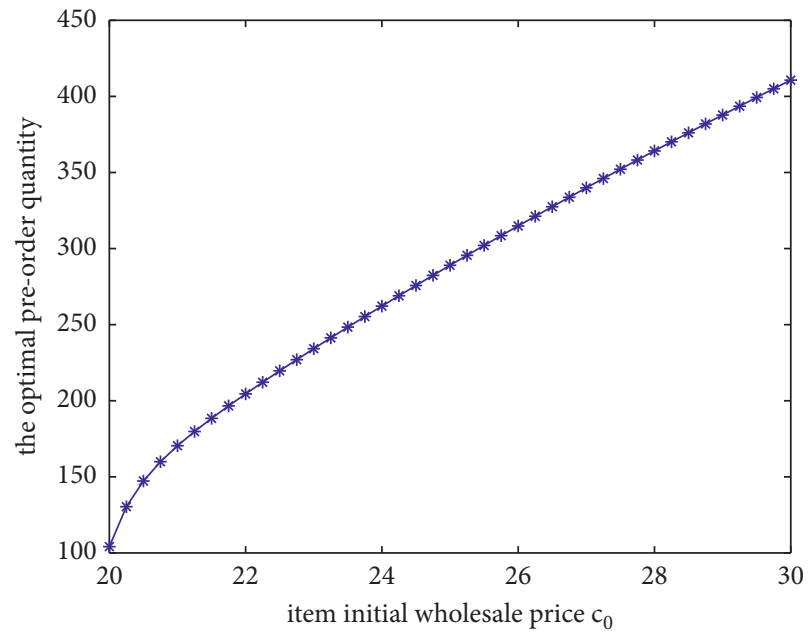

FiguRE 7: Influence of $c_{0}$ on the retailer's preordering quantity.

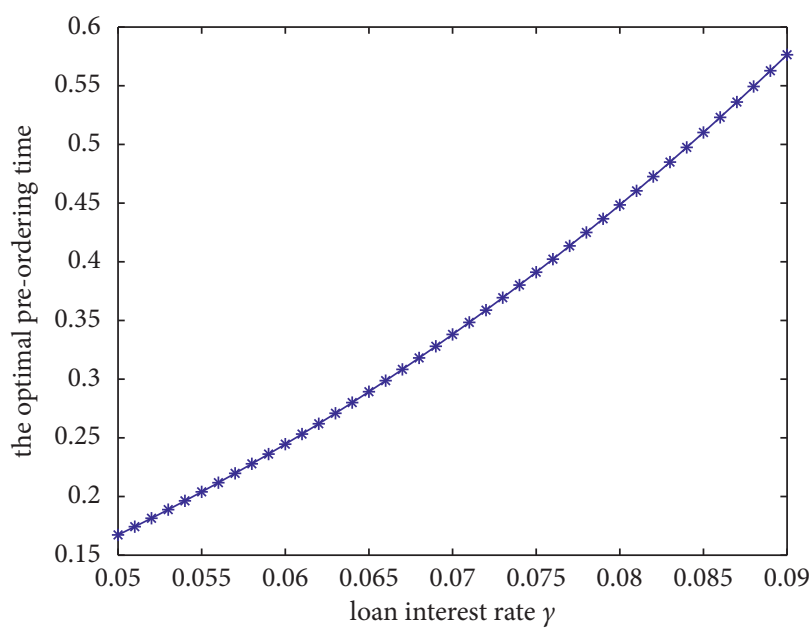

Figure 8: Influence of $\gamma$ on the retailer's preordering time.

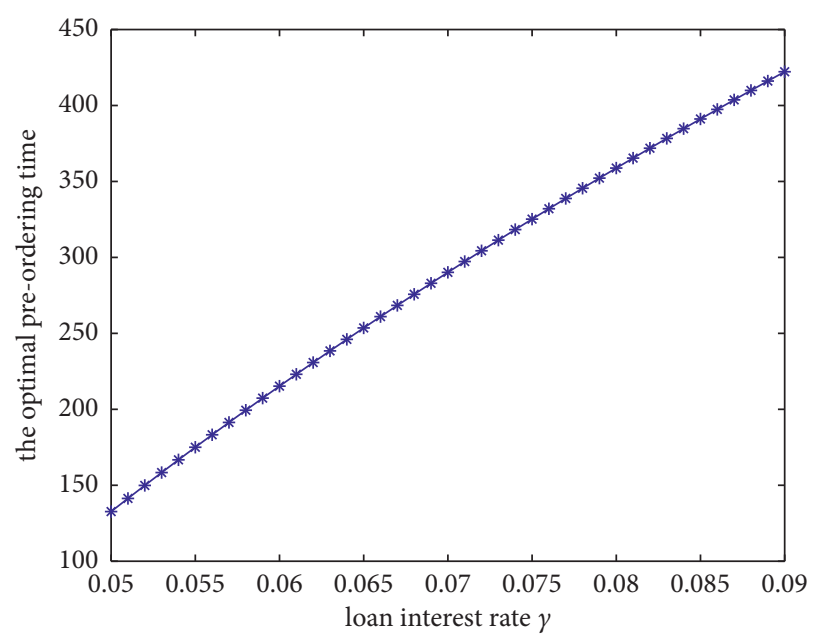

FIGURE 9: Influence of $\gamma$ on the retailer's preordering quantity. 


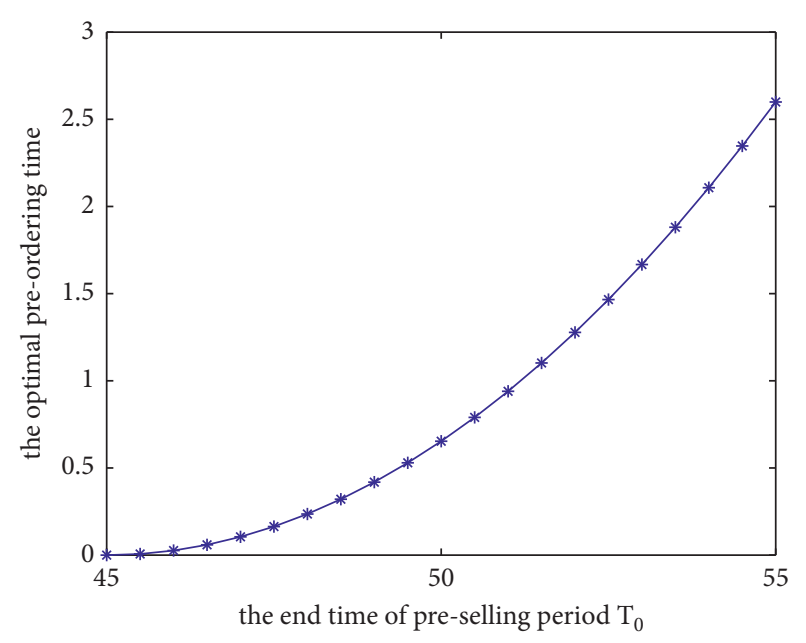

FIGURE 10: Influence of $T_{0}$ on the retailer's preordering time.

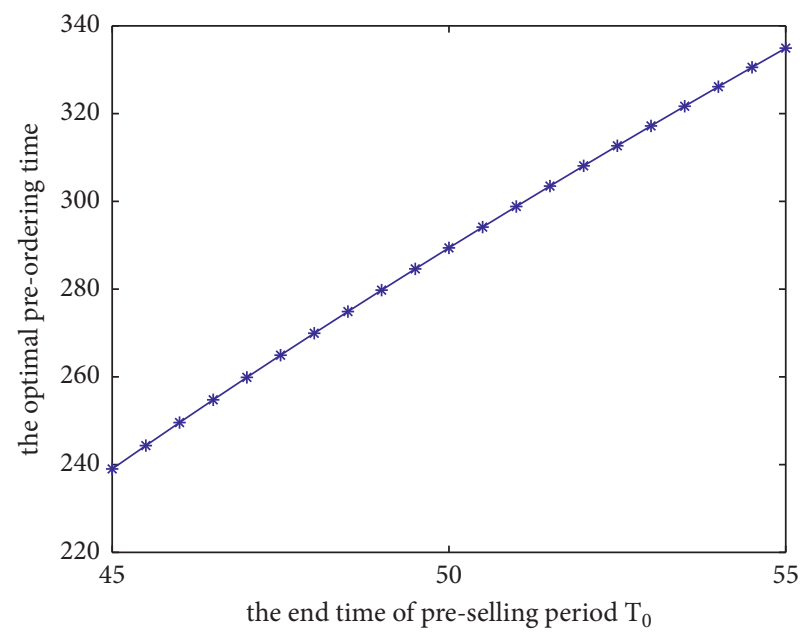

FIgURE 11: Influence of $T_{0}$ on the retailer's preordering quantity.

Example 2. Considering the preorder inventory system with $\alpha=0.95, b=70, c_{0}=25, \gamma=0.07, \tau=0.3$, and $r=15$, we let $T_{0}$ increase from 45 to 55 , while the market demand $D$ obeys the exponential distribution with probability density function $f(x)=1 / 150 \exp (-x / 150), x \in[0,+\infty)$.

For this inventory mechanism, the numerical results are shown in Figures 10 and 11, from which we can see that, when $T_{0}$ goes from 45 to 55 , the retailer's preordering time is increasing in $T_{0}$ and the retailer's optimal preordering quantity is also increasing in $T_{0}$.

Example 3. Considering the preorder inventory system with $\alpha=0.95, b=70, c_{0}=25, \gamma=0.07, r=15$, and $T_{0}=50$, we let $\tau$ increase from 0.2 to 0.4 , while the market demand $D$ obeys the exponential distribution with probability density function $f(x)=1 / 150 \exp (-x / 150), x \in[0,+\infty)$.

For this inventory mechanism, the numerical results are shown in Figures 12 and 13, from which we can see that, when $\tau$ goes from 0.2 to 0.4 , the retailer's preordering time is decreasing in $\tau$, and the retailer's optimal preordering

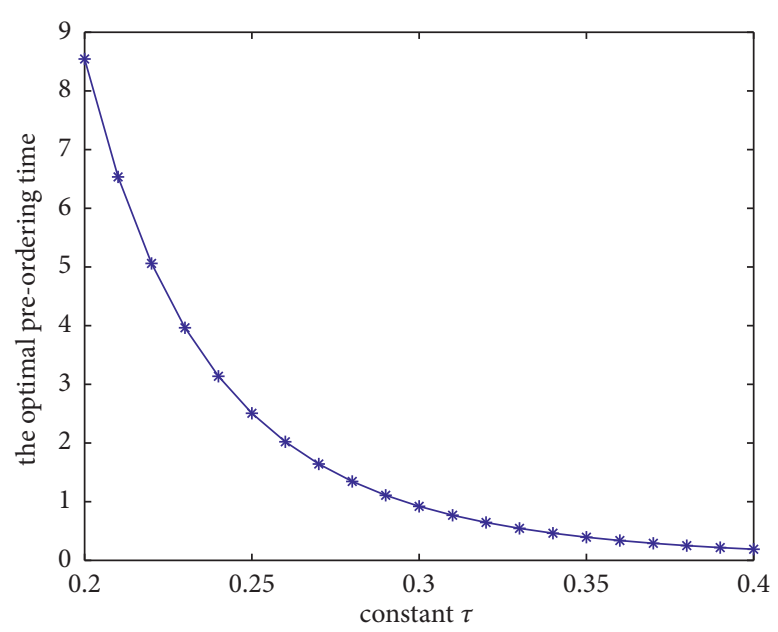

FIgURE 12: Influence of $\tau$ on the retailer's preordering time.

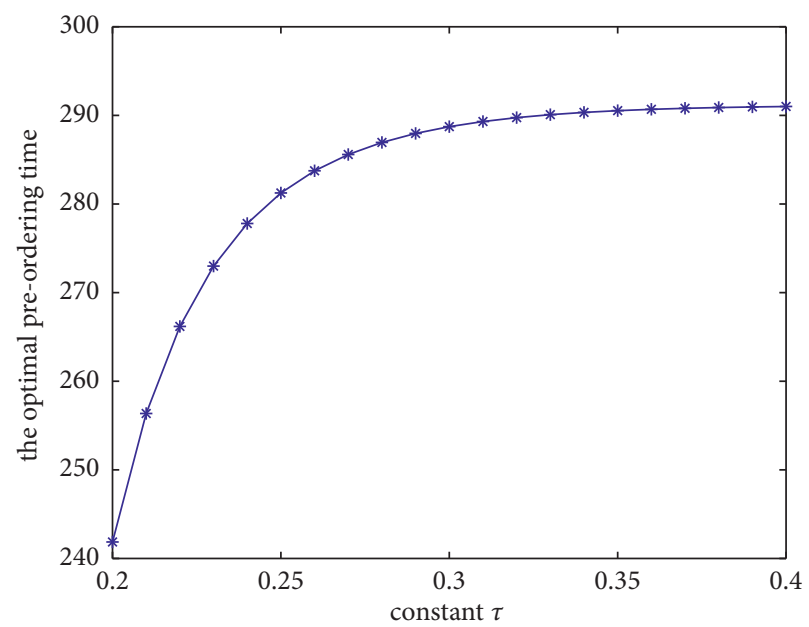

FIGURE 13: Influence of $\tau$ on the retailer's preordering quantity.

quantity is also increasing in $\tau$, and the increase rate is slower and slower.

From the numerical experiments on the involved parameter sensitivity analysis, we can see that the retailer's confidence level $\alpha$, item selling price $b$, item initial wholesale price $c_{0}$, and loan interest rate $\gamma$ have a larger influence on retailer's preordering strategy, while the end time of preselling period $T_{0}$ and wholesale price increasing coefficient $\tau$ have a less influence on the retailer's preordering strategy. The retailer's optimal preordering time is decreasing in $\alpha, c_{0}$, and $T_{0}$, while increasing in $b$. The retailer's optimal preordering quantity is increasing in $\alpha, \gamma$, and $T_{0}$, while decreasing in $c_{0}$.

\section{Conclusion}

For the concerned inventory mechanism, the planning horizon consists of two periods-preselling period and spot selling period. During the preselling period, the wholesale price of the item gradually increases with time; based on minimizing the legacy loss via $\mathrm{CVaR}$ measure, we 
established a risk-averse' optimal preorder strategy for the newsvendor model and gave the retailer's optimal preordering strategy. Some numerical examples were provided to show the sensitivity of the involved parameters in the model, in which can see that the retailer's confidence level, item selling price, item initial wholesale price, and the loan interest rate are crucial ingredients in the retailer's preordering problem.

From the result of numerical experiments in this study, the high confidence level will make the retailer preorder earlier and preorder more items. If the initial wholesale price is high or the wholesale price increases rapidly, the retailer should make preorder earlier and order more items to reduce the legacy loss. The high selling price will make the retailer preorder later and preorder more items to reduce the legacy loss. The high loan interest rate will make retailer preorder earlier and order less items. The longer the duration of the preselling period is, more preorder items should be made.

Certainly, the preordering model considered in this paper assumes that the probability distribution of the demand during the preselling period is fixed. However, the demand distribution may be more and more clear with the time during the period. Thus, the research of the issue that the fluctuation of demand is getting weaker and weaker with the time is more significant.

\section{Data Availability}

The data used to support the findings of this study are available from the corresponding author upon request.

\section{Conflicts of Interest}

The authors declare that there are no conflicts of interest regarding the publication of this paper.

\section{Authors' Contributions}

All authors equally contributed to this paper and read and approved the final manuscript.

\section{Acknowledgments}

This project was supported by the National Natural Science Foundation of China (12071250).

\section{References}

[1] F. J. Arcelus, S. Kumar, and G. Srinivasan, "Pricing, rebate, advertising and ordering policies of a retailer facing pricedependent stochastic demand in newsvendor framework under different risk preferences," International Transactions in Operational Research, vol. 13, no. 3, pp. 209-227, 2006.

[2] F. M. Bass, "A new product growth model for consumer durables," Management Science, vol. 50, no. 12, pp. 1825-1832, 2004.

[3] Y. Bian, D. Lemoine, T. G. Yeung, and N. Bostel, "Two-level uncapacitated lot-sizing problem considering the financing cost of working capital requirement," Frontiers of Engineering Management, vol. 7, no. 2, pp. 248-258, 2020.
[4] Y. Cheng, H. Li, and A. Thorstenson, "Advance selling with double marketing efforts in a newsvendor framework," Computers \& Industrial Engineering, vol. 118, pp. 352-365, 2018.

[5] S Schroeder, "Apple's iPhone $\mathrm{X}$ is now available for pre-order," 2017, https://mashable.com/article/iphone-X-preorderslive.

[6] S. Tech, "Xiaomi launched its first generation mobile phone MIUI today, dual-core CPU $1.5 \mathrm{G} \mathrm{Hz}$ main frequency mobile phone is priced at $1999 \mathrm{CNY}$," 2011, https://tech.sina.com.cn/ mobile/n/2011-08-16/15355936576.shtml.

[7] T. Boyaci and Ö. Özer, "Information acquisition for capacity planning via pricing and advance selling: When to stop and act," Operations Research, vol. 58, no. 5, pp. 1328-1349, 2010.

[8] G. P. Cachon, "The allocation of inventory risk in a supply chain: Push, pull, and advance-purchase discount contracts," Management Science, vol. 50, no. 2, pp. 222-238, 2004.

[9] J. D. Dana Jr, "Advance-Purchase Discounts and Price Discrimination in Competitive Markets," Journal of Political Economy, vol. 106, no. 2, pp. 395-422, 1998.

[10] S. Fay and J. Xie, "The economics of buyer uncertainty: Advance selling vs. probabilistic selling," Marketing Science, vol. 29, no. 6, pp. 1040-1057, 2010.

[11] Y. Gao, Z. Feng, and S. Zhang, "Managing supply chain resilience in the era of VUCA," Frontiers of Engineering Management, vol. 8, no. 3, pp. 465-470, 2021.

[12] X. Zhao and K. E. Stecke, "Pre-orders for new to-be-released products considering consumer loss aversion," Production and Operations Management, vol. 19, no. 2, pp. 198-215, 2010.

[13] S. M. Gilbert and V Cvsa, "Strategic commitment to price to stimulate downstream innovation in a supply chain," European Journal of Operational Research, vol. 179, no. 150, pp. 617-639, 2003.

[14] J. Nasiry and I. Popescu, "Advance selling when consumers regret," Management Science, vol. 58, no. 6, pp. 1160-1177, 2012.

[15] A. Tezel, E. Papadonikolaki, I. Yitmen, and P. Hilletofth, "Preparing construction supply chains for blockchain technology: An investigation of its potential and future directions," Frontiers of Engineering Management, vol. 7, no. 4, pp. 547-563, 2020.

[16] M. Wu, S. X. Zhu, and R. H. Teunter, "Advance selling and advertising: a newsvendor framework," Decision Sciences, vol. 52, no. 1, pp. 182-215, 2021.

[17] J. Xie and S. M. Shugan, "Electronic tickets, smart cards, and online prepayments: when and how to advance sell," Marketing Science, vol. 20, no. 3, pp. 219-243, 2001.

[18] S. M. Shugan and J. Xie, "Advance selling for services," California Management Review, vol. 46, no. 3, pp. 37-54, 2004.

[19] P. Gundepudi, N. Rudi, and A. Seidmann, "Forward versus spot buying of information goods," Journal of Management Information Systems, vol. 18, no. 2, pp. 107-131, 2001.

[20] A. O. Brown, C. S. Tang, and C. S. Tang, "The impact of alternative performance measures on single-period inventory policy," Journal of Industrial \& Management Optimization, vol. 2, no. 3, pp. 297-318, 2006.

[21] C. Wang and S. Webster, "The loss-averse newsvendor problemઐ," Omega, vol. 37, no. 1, pp. 93-105, 2009.

[22] J. Wu, J. Sun, and L. Liang, "Methods and applications of DEA cross-efficiency: Review and future perspectives," Frontiers of Engineering Management, vol. 8, no. 2, pp. 199-211, 2021. 
[23] W. Xue, L. Ma, and H. Shen, "Optimal inventory and hedging decisions with CVaR consideration," International Journal of Production Economics, vol. 162, pp. 70-82, 2015.

[24] R. T. Rockafellar and S. Uryasev, "Optimization of conditional value-at-risk," The Journal of Risk, vol. 2, no. 3, pp. 21-41, 2000.

[25] R. T. Rockafellar and S. Uryasev, "Conditional value-at-risk for general loss distributions," Journal of Banking \& Finance, vol. 26, no. 7, pp. 1443-1471, 2002.

[26] Y. Chen, M. Xu, and Z. G. Zhang, "Technical Note-A RiskAverse Newsvendor Model Under the CVaR Criterion," Operations Research, vol. 57, no. 4, pp. 1040-1044, 2009.

[27] X. Xu, Z. Meng, R. Shen, M. Jiang, and P. Ji, "Optimal decisions for the loss-averse newsvendor problem under CVaR," International Journal of Production Economics, vol. 164, pp. 146-159, 2015.

[28] X. Xu, Z. Meng, P. Ji, C. Dang, and H. Wang, "On the newsvendor model with conditional value-at-risk of opportunity loss," International Journal of Production Research, vol. 54, no. 8, pp. 2449-2458, 2016.

[29] X. Xu, H. Wang, C. Dang, and P. Ji, "The loss-averse newsvendor model with backordering," International Journal of Production Economics, vol. 188, pp. 1-10, 2017.

[30] X. S. Xu, F. T. S. Chan, and C. K. Chan, "Optimal option purchase decision of a loss-averse retailer under emergent replenishment," International Journal of Production Research, vol. 57, no. 4, pp. 4594-4620, 2019.

[31] C. Li and F. Zhang, "Advance Demand Information, Price Discrimination, and Preorder Strategies," Manufacturing \& Service Operations Management, vol. 15, no. 1, pp. 57-71, 2013.

[32] B. Feng and Q. Ye, "Operations management of smart logistics: A literature review and future research," Frontiers of Engineering Management, vol. 8, no. 3, pp. 344-355, 2021.

[33] Z. Kevin Weng and M. Parlar, "Integrating early sales with production decisions: Analysis and insights," IIE Transactions, vol. 31, no. 11, pp. 1051-1060, 1999.

[34] X. Xu, C. K. Chan, and A. Langevin, "Coping with risk management and fill rate in the loss-averse newsvendor model," International Journal of Production Economics, vol. 195, pp. 296-310, 2018.

[35] R. Yin, Y. Aviv, A. Pazgal, and C. S. Tang, "Optimal markdown pricing: Implications of inventory display formats in the presence of strategic customers," Management Science, vol. 55, no. 8, pp. 1391-1408, 2009. 